\title{
田
}

\section{PRIVATIZAÇÃO E PRECARIZAÇÃO DA POLÍTICA DE EDUCAÇÃO SUPERIOR NO BRASIL - IMPACTOS PARA A FORMAÇÃO PROFISSIONAL EM SERVIÇO SOCIAL}

\author{
PRIVATIZATION AND PRECARIZATION OF THE HIGHER EDUCATION \\ POLICY IN BRAZIL - IMPACTS FOR PROFESSIONAL FORMATION \\ IN SOCIAL WORK
}

\section{Lucimara Perpétua dos Santos Benatti ${ }^{1}$ Patrícia Soraya Mustafa ${ }^{2}$}

\section{RESUMO}

O artigo apresenta um debate sobre a política de educação superior no Brasil em tempos de governos que se movem a partir do ideário neoliberal, elucidando os impactos dessa orientação para a política de educação superior, e para formação de Assistentes Sociais. O debate que se delineia é fruto de estudos teóricos e empíricos das autoras, e demonstra como principais resultados a privatização e precarização da política educacional, com ênfase no ensino superior, o que compromete a qualidade da formação em Serviço Social. Entretanto, elucida a importância do papel da Associação Brasileira de Ensino e Pesquisa em Serviço Social (ABEPSS) como resistência à esta precarização do ensino superior, especialmente na formação de assistentes sociais, e deixa claro o seu compromisso, em sua atual gestão (2015-2016): "Ousadia e sonhos em tempos de resistência".

Palavras-chave: Neoliberalismo. Política de Educação Superior no Brasil. Formação Profissional em Serviço Social. Privatização. ABEPSS.

\footnotetext{
1 Doutora em Serviço Social. Professora da Universidade dos Grandes Lagos (UNILAGO) de São José do Rio Preto/SP.

2 Doutora em Serviço Social. Professora do Departamento de Serviço Social da Universidade Estadual Paulista "Júlio de Mesquita Filho" - UNESP/Franca/SP.
} 


\section{temporollis}

\section{ABSTRACT}

This paper presents a discussion about higher education policy in Brazil in times of governments moving from the neoliberal ideas, elucidating the impact of this guidance for higher education policy and the formation in social worker. This discussion emerges from the results of theoretical and empirical studies of the authors, and demonstrate how major results the privatization and casualization of educational policy, with emphasis on higher education, which compromises the quality of formation in social work. However, elucidates the importance of the role of the Association of Education and Research in Social Work (ABEPSS) as resistance to this precariousness of higher education, especially in the formation of the social workers, and makes clear its commitment in its present management (2015- 2016): "Boldness and dreams in endurance times."

Keywords: Neoliberalism. Policy of Higher Education in Brazil. Professional training in Social Work. Privatization. ABEPSS.

Submissão - 13/09/2016 Aceite - 13/01/2017
A

\section{Introdução}

Este artigo se propõe a debater os rumos da Política de Educação Superior no Brasil e seus impactos na formação dos assistentes sociais brasileiros, em tempos de capitalismo monopólico financeirizado e sob a égide dos ideais neoliberais.

Para tanto, inicialmente, se dará as bases para essa discussão, na medida em que se demonstrará como este modelo econômico se configura atualmente e quais as repercussões que traz para o campo dos direitos sociais, destacando o direito à educação.

Logo após, o artigo problematiza a política educacional brasileira, enfatizando a Reforma Universitária dos anos de 1960, e, apontando suas reatualizações, bem como suas determinações a partir das contrarreformas neoliberais. E, como a formação dos assistentes sociais não está descolada deste contexto, ao contrário, é impactada pelas orientações políticas e econômicas de cada governo, se analisará quais os problemas, embates e desafios para a formação profissional em Serviço Social que o presente contexto aponta.

Cabe mencionar que o presente artigo é fruto de estudos teóricos e empíricos das duas autoras, sendo que uma delas se debruçou sobre esta temática específica da política de educação superior 
em sua tese de doutorado, assim, as reflexões delineadas aqui advém destes estudos.

Por fim este artigo elucidará alguns desafios postos para a formação profissional dos assistentes sociais brasileiros, bem como as ações já delineadas pela Associação Brasileira de Ensino e Pesquisa em Serviço Social (ABEPSS) ${ }^{3}$, na atual gestão (2015-2016), no sentido de enfrentar os principais problemas que perpassam no tempo presente a formação de novos e novas assistentes sociais.

\section{0 estado brasileiro neoliberal e a tendência das políticas sociais nos últimos governos}

O Brasil na década de 1980 sai de um período de 20 anos de Ditadura Militar e constitui-se como um Estado democrático, aprovando uma nova Carta Magna em 1988 - a qual traz em seu bojo a tentativa de instaurar um Estado Social - era a primeira vez na história brasileira que se instituía em lei uma proposta de Seguridade Social, abarcando o direito à saúde, previdência social e assistência social, e um rol de direitos sociais como o direito à educação, por exemplo, expresso no artigo $6^{\circ}$ desta Carta.

Entretanto, no mesmo momento em que o Brasil tenta, ainda que legalmente, erigir o seu Estado Social, o pensamento neoliberal começa a se impor para a América Latina através do Consenso de Washington, documento produzido em um encontro que ocorreu em Washington (EUA), em 1989, com a participação de economistas do Banco Mundial, Fundo Monetário Internacional (FMI), Departamento do Tesouro Norte-americano, o qual apregoa um receituário de medidas neoliberais à América Latina sob a justificativa de tirar os países deste continente da crise econômica que os assolava nos anos de 1980. Entre as principais medidas estão: a privatização, a desregulamentação do mercado, financeirização da economia, políticas sociais restritas, flexibilização das relações de trabalho.

Entretanto, faz-se necessário considerar que o neoliberalismo,

3 A ABEPSS é uma entidade de natureza acadêmico-científica que, em âmbito nacional, coordena e propõe a política de formação profissional dos assistentes sociais brasileiros. Foi fundada no Brasil em 1948 como Associação Brasileira de Ensino em Serviço Social (ABESS), e alterada para ABEPSS em dezembro de 1998. 


\title{
temporollis
}

enquanto ideário político e econômico, foi implementado em cada país a partir de suas particularidades, e como elucida (CASTELO, 2013) considerando a correlação de forças presente em cada estado nacional. No Estado brasileiro o neoliberalismo desponta a partir da década de 1990, após um período de profunda crise econômica e de ditadura militar. De acordo com Mattoso (1995, p.143, grifos do autor):

\begin{abstract}
O neoliberalismo não adquiriu força crescente nos primeiros anos da década de 90 somente porque imposto pelos EUA e organismos internacionais, mas sim porque opção de importantes setores empresariais (industriais e agrícolas), classes médias e, inclusive, de parcelas dos trabalhadores brasileiros que apoiaram formalmente as políticas do governo Collor. Estes setores, encantados com o canto da sereia da modernização conservadora, com o discurso ideológico que vislumbrava o fim da história e dos espaços nacionais e o início do reino do consumismo, pensavam poder, enquanto comerciantes e consumidores de quaisquer produtos importados ou produtores de um nicho ou de uma ilha de excelência e produtividade, integrar-se à economia mundial, pouco se importando caso isso gerasse ainda maiores desigualdades, ruptura do tecido social, da democracia ou mesmo da nacionalidade.
\end{abstract}

No entanto, como atestam os autores do livro Pós-neoliberalismo: as políticas sociais e o Estado democrático de Sader, Gentili e Boron (1995), esta doutrina não logrou a recuperação da economia conforme prometia, tampouco melhoras nas condições de trabalho e de vida, ao contrário, os índices de pobreza e desigualdade social agravaram-se. Estes maus resultados levaram os neoliberais ortodoxos a reverem o caminho, sem, no entanto, cambiarem de direção. Neste sentido, dá-se início a "refuncionalização do Estado" (CASTELO, 2013), o que significa que este ator passaria a regular as atividades econômicas e passaria a atuar "[...] em parceria com o setor privado, políticas sociais emergenciais, focalizadas e assistencialistas [...]" (CASTELO, 2013, p. 244), o intuito era continuar assegurando as taxas de acumulação do capital e abrandar as expressões da questão social.

Assim as políticas sociais configuram-se na dualidade público-privado e são políticas cunhadas pela focalização aos setores mais pobres.

Segundo esses pressupostos o que se verifica, então, é a configuração do que Castelo (2013, p. 247) denomina de "[...] segunda 
variante ideológica do neoliberalismo - chamado social-liberalismo", em síntese, uma fusão entre Estado e mercado com o propósito de combinar crescimento econômico e ganhos sociais ao mesmo tempo.

Nesta direção é que caminham os governos Luís Inácio Lula da Silva (2003-2010) e Dilma Rousseff (2011-2016), em seu primeiro mandato e no curto e interrompido segundo mandato ${ }^{4}$.

Já em princípios do "governo" golpista" de Michel Temer, os ventos que começam a soprar são assustadores, tendo em vista que conforme indicam os principais documentos orientadores de seu governo - Ponte para o Futuro e Travessia Social - haverá uma interrupção do social-neoliberalismo (CASTELO, 2013), e início de uma era de radicalização dos princípios liberais, sob o mote do ajuste fiscal e da privatização.

\section{Política de educação superior no Brasil: tempos de reformas neo- liberais, determinantes internacionais e empresariamento educacio- nal}

A educação superior no Brasil na atualidade está permeada por heranças do período autoritário (1964-1985), em especial do período de reforma universitária ${ }^{6}$ que se deu em 1968. Minto e Minto (2012) discutem sobre os legados da reforma universitária de 1968 e salientam quatro eixos de análises que foram mantidos deste período aos dias atuais, que são: 1) fragmentação da educação e acesso diferenciado a níveis e etapas do ensino; 2) descaracterização da indissociabilidade ensino, pesquisa e extensão; 3) privatização como política oficial para o ensino superior; 4) autoritarismo e repressão sistemática nas

4 Dilma Rousseff acaba de ser destituída do governo, após sofrer um injusto processo de impeachment, votado em 31 de agosto de 2016, dando-se início a partir de então, ao "governo" golpista de Michel Temer.

5 A palavra governo está entre aspas, pois, não reconhecemos a legitimidade deste, uma vez que a tomada de poder por Michel Temer se deu via um processo golpista, engendrado pela elite brasileira e seu cão de guarda, a mídia, que culminou na destituição de Dilma Rousseff da presidência.

6 A reforma universitária mobilizou, na década de 1960, amplos setores da sociedade e, na perspectiva dos estudantes, era um momento de ampliação e democratização do ensino superior em uma sociedade desigual e com uma organização educacional bem seletiva e excludente. Porém, os rumos tomados foram bem diferentes dos idealizados. 


\title{
temporalis
}

instituições de ensino superior.

Destacamos, especialmente, o terceiro eixo de análise dos autores em referência (privatização como política oficial para o ensino superior), pois, como já se demonstrou neste artigo, um novo impulso à privatização ocorreu a partir dos anos 1990, assim, constrói-se uma nova arquitetura para a educação mundial. Nesse sentido, no Brasil, alguns pilares são reforçados nesta óptica da privatização, substituindo o direito por serviço, incidindo na mercantilização da educação. Além da privatização, a lei em vigor (Lei $n^{\circ} 7.200 / 2006$ ) permite que as Instituições de Ensino Superior (IES), denominadas sem fins lucrativos, recebam recursos estatais na forma de: a) subvenção social, b) auxílio; c) contribuição; d) convênio; e) termo de parceria; f) imunidade de impostos; g) imunidade de contribuições sociais; h) isenção; i) incentivo fiscal ao doador; j) voluntariado. (BEHRING, 2008).

Para Leher (2011) outra inquietação se faz presente quando pretende questionar-se: qual a função da universidade em um país capitalista dependente? O autor, fundamentado em Florestan Fernandes analisa a revolução burguesa empreendida no Brasil, de cima para baixo, e afirma que esta dependência está legitimada, também, pelas frações burguesas locais. Expondo seus argumentos afirma que:

\begin{abstract}
Florestan Fernandes, distintamente, aponta que a dominação externa necessita da participação de frações burguesas locais. Embora as frações locais sejam subordinadas, os nexos que as vinculam com as frações hegemônicas do capital são imprescindíveis para o capitalismo e, por isso, conceber as frações burguesas locais como progressistas é uma forma de aderir ao padrão de exploração e de expropriação dominantes. (LEHER, 2011, p. 19).
\end{abstract}

Hoje, temos o neoliberalismo, a mundialização do capital e a financeirização que subsumiram a educação para um espaço quase que estritamente de âmbito privado. Assim, Neves e Pronko (2008), também, subsidiadas pela argumentação teórica de Florestan Fernandes sobre os países de "capitalismo dependente", esclarecem que esses países são denominados pelos organismos internacionais de países "em desenvolvimento-transição", entre eles, incluem os países da América Latina, da África e da Ásia - bem como, as ex-repúblicas socialistas da Europa e da Ásia central, pois, estão em processo de conformação às relações sociais capitalistas. O ano de 1994 foi decisivo 


\section{tempordis}

na redefinição estratégica do Banco Mundial (BM) e da Organização das Nações Unidas para a Educação, a Ciência e a Cultura (UNESCO) para a formação do trabalho nestes países, então, a meta prioritária de "educação para todos", desde os anos 1980 começa a ser direcionada para a massa da classe trabalhadora - uma educação superior de novo tipo no século XXI. Segundo as recomendações que o BM advogou para,

[...] a substituição do modelo de estruturação da educação superior em vigor nos países periféricos, de influência europeia, por um modelo mais flexível, mais próximo do modelo estadunidense, composto por universidades, colleges, politécnicos e centros de formação técnico-profissional, que pudesse dar conta das necessidades do 'mundo em transformação'. A implementação desse novo modelo estava condicionada, a priori, à 'diminuição do gasto público' e ao aumento da participação da iniciativa privada (BM apud NEVES; PRONKO, 2008, p. 106).

E, sobre a Política de Educação Superior no Brasil, há que se considerar que a reforma do Estado (desde a década de 1960) compõe o marco dos determinantes recomendados por estes organismos multilaterais - BM e Fundo Monetário Internacional (FMI) que, segundo lamamoto (2000, p. 35), "[...] cria o suporte normativo necessário para viabilizar a reforma educacional." $\mathrm{E}$, um destes normativos apresenta-se na Lei de Diretrizes e Bases da Educação Nacional (LDB) Lei ${ }^{\circ}$ 9.394, de 20/12/1996 (BRASIL, 1996), que possibilita vicissitudes neste contexto brasileiro, ampliando as possibilidades de oferta de educação privada, garantindo, em especial, a destinação de recursos públicos a entidades filantrópicas, confessionais e comunitárias. Neste sentido, estes organismos multilaterais dominam esse novo movimento, sendo instrumentos políticos e ideológicos que conferem ao mundo uma lógica de pensar, agir e de se posicionar, condicionando os países membros a implantar formas de expropriação dos direitos sociais e soberania nacional.

A fragmentação educacional no governo Fernando Henrique Cardoso (FHC) foi bem expressiva, uma vez segregando a divisão entre instituições de ensino e de pesquisa, foram criadas instituições não universitárias, majoritariamente privadas, passando a serem denominadas de Centros Universitários, Faculdades Integradas, Faculdades, Institutos e Escolas Superiores - mantendo um modelo de educação superior pretendido pelos setores conservadores da sociedade. En- 


\section{temporollis}

tendida como a possibilidade de intervenção privada no planejamento e na execução de suas políticas, os organismos internacionais definem que,

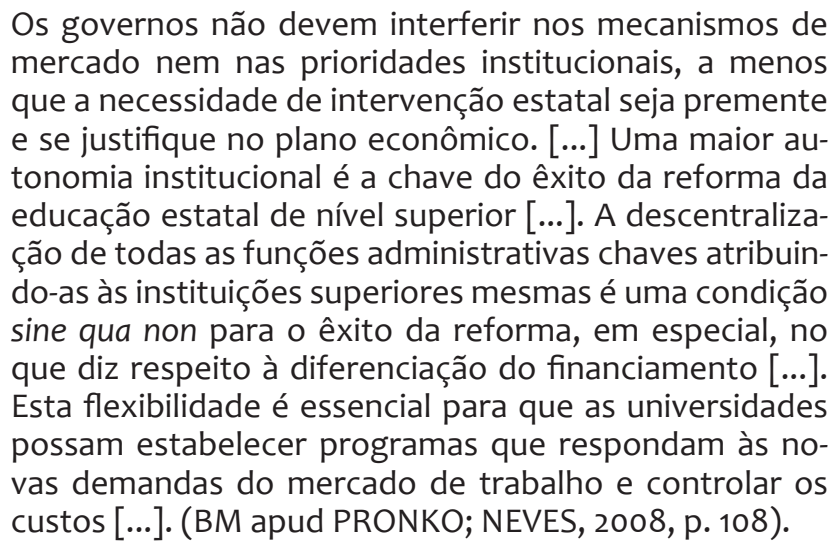

Já no governo Lula da Silva a política de educação, entre outros objetivos, colocou em prática os princípios definidos no Livro Verde e no Livro Branco da Ciência e da Tecnologia do governo FHC e as diretrizes do BM e da Unesco para a educação superior, inserindo, nos anos 2000, o papel do Brasil sob esta ordem - em suma, direcionando a educação para a "sociedade do conhecimento" - a sociedade do século XXI (NEVES; PRONKO, 2008, p. 72), descaracterizando a educação para a formação humana, política, cultural, social e emancipatória.

O arcabouço jurídico e normativo necessário para o aprofundamento da Reforma da Educação Superior Brasileira foi, então, edificado no governo FHC, porém, aprofundado no primeiro ano do governo Lula e solidificado no seu segundo mandato, sobretudo, com o Projeto de Lei $n^{\circ} 7.200$, de 2006 , que se propôs a normatizar a educação superior, regular o âmbito federal de ensino e alterar a LDB (art. $1^{\circ}$ ). O Sindicato Nacional dos Docentes das Instituiçõos de Ensino Superior (ANDES-SN) salienta em um documento 7 que a educação superior no Brasil constitui anomalia, pelo menos, em relação a duas características: a privatização impressionante e crescente do sistema e a sua fragmentação. Neste interregno, cabe destacar leis que dão concretude à reforma, quais são, Lei n ${ }^{\circ} 10.861 / 2004$, que instituiu o Sistema Nacional de Avaliação do Ensino Superior (SINAES),

7 Este documento é veiculado pelo Andes-SN, sob o título: A Educação Superior em Perigo! Para aprofundamentos, Andes-SN (ANDES-SN, 2006). 


\section{tempordis}

estabelecendo a avaliação da instituição, de cursos e dos discentes através do Exame Nacional de Desempenho do Estudante (ENADE), seguindo critérios normativos e punitivos. A Lei $n^{\circ} 11.096 / 2005$, que normatiza o Programa Universidade para Todos (PROUNI), além do Financiamento Estudantil (FIES) ${ }^{8}$ - expressão cabal do investimento público no mercado educacional privado erigido, e como finalidade, o lucro e enriquecimento dos empresários da educação, nos últimos anos. Estes investimentos seduzem os estudantes da classe trabalhadora a buscar o sonho da educação superior, haja vista que a educação pública não acolhe de forma igualitária essa classe.

Constata-se que o crescimento das IES privadas de 1995-2001 (período do governo $\mathrm{FHC}$ ) foi de $76,6 \%$, contra a retração no número de criação de IES públicas que ficou com $-12,8 \%$. E, o número de matrículas na modalidade presencial cresceu $34,1 \%$ nas IES públicas e nas privadas somaram-se 97,4\%. No governo Lula da Silva (2003-2010), a expansão da educação superior continuou crescente na iniciativa privada e dando impulso à consolidação dos cursos de graduação na modalidade EaD, conforme o Decreto $n^{\circ} 5.622$, de 19 de dezembro de 2005. Assim, o aumento das IES privadas no período de 2003-2009 foi de $25,2 \%$ e, das IES públicas houve um crescimento de $18,3 \%$; sendo o crescimento das matrículas nas IES privadas na margem de $36,8 \%$ e nas públicas de $18,9 \%$. Porém, os dados mais estarrecedores são relativos à expansão de $333,8 \%$ de matrículas na modalidade EaD nas IES públicas e de $6.483,8 \%$ nas IES privadas, conforme podemos constatar na tabela abaixo:

Tabela 1 - Evolução das IES, Matrículas Presenciais e a Distância na Educação Superior, por categoria administrativa - Brasil $1995 / 2009$

8 Objetivando ampliar o mercado educacional, estagnado em virtude da concentração de renda, o governo Lula da Silva aumentou os aportes de recursos públicos para o FIES (criado em 2001), cuja taxa de juros foi reduzida a perto de $30 \%$ da taxa básica de juros (SELIC): a diferença seria coberta pelo Estado. A isenção tributária ao setor mercantil, possível com a criação do PROUNI (2004), abriu caminho para o ingresso dos fundos de investimento (private equity) no setor educacional, possibilitando uma frenética onda de fusões e aquisições, grande parte pelo capital estrangeiro, promovendo inédita concentração e centralização das corporações educacionais (LEHER, 2014). 


\begin{tabular}{|c|c|c|c|c|c|c|}
\hline \multirow{2}{*}{ Ano } & \multicolumn{2}{|c|}{ IES } & \multicolumn{2}{|c|}{ Matriculas Presenciais } & \multicolumn{2}{|c|}{ Matriculas EAD } \\
\hline & Pública & Privada & Pública & Privada & Pública & Privada \\
\hline 1995 & 210 & 684 & 700.540 & 1.059 .163 & - & - \\
\hline 1997 & 211 & 689 & 759.182 & 1.186 .433 & - & - \\
\hline 1999 & 192 & 905 & 832.022 & 1.537 .923 & - & - \\
\hline 2001 & 183 & 1.208 & 939.225 & 2.091 .529 & 5.359 & - \\
\hline 2003 & 207 & 1.652 & 1.136 .370 & 2.750 .652 & 39.804 & 10.107 \\
\hline 2005 & 231 & 1.934 & 1.192 .189 & 3.260 .967 & 53.117 & 61.525 \\
\hline 2007 & 249 & 2.032 & 1.240 .968 & 3.639 .413 & 92.873 & 276.893 \\
\hline 2009 & 245 & 2.069 & 1.351 .168 & 3.764 .728 & 172.696 & 665.429 \\
\hline$\Delta(\%)$ 95-01 & $-12,8$ & 76,6 & 34,1 & 97,4 & .. & .. \\
\hline$\Delta(\%)$ 03-09 & 18,3 & 25,2 & 18,9 & 36,8 & 333,8 & $6.483,8$ \\
\hline$\Delta(\%) 95-09$ & 16,6 & 202,5 & 92,9 & 255,4 & .. &.. \\
\hline
\end{tabular}

Fonte: CEOLIN, SILVA (2013, p. 166).

No primeiro mandato do governo, Dilma Rousseff (2011-2014), no que tange ao novo Plano Nacional de Educação (PNE - 2011/2020)', aprovado no Senado em 17/12/2013, temos a consagração da prevalência do setor privado no financiamento da educação pública, sobretudo porque se apagou a qualificação - "público", em detrimento das parcerias público-privadas. Evangelista e Leher (2012 apud LEHER, 2014, p. 1), afirmam que,

É possível sustentar que o PNE do governo Dilma expressa uma mudança estrutural na educação brasileira, consolidando um objetivo que não pode mais ser confundido com os dos proprietários tradicionais das escolas privadas ou o da Igreja Católica, sujeitos importantes nos embates da LDB de 1961; antes, afirma os anseios do setor financeiro que atualmente se apropria de vastos domínios dos negócios educacionais e, como assinalado, do capital como um todo [...].

9 Lembrando que o PNE (PL n ${ }^{\circ}$ 8.035/2010) foi elaborado no governo Lula da Silva em conformidade com o mainstream da agenda educacional do capital, incorporando, na educação básica, as proposições do TPE, os interesses das corporações educativas (liberalização e acesso aos recursos públicos), os anseios do Sistema S (controle da educação profissional) e os grandes delineamentos das agências internacionais, notadamente no que se refere à avaliação centralizada e referenciada nas competências (OCDE/PISA). (LEHER, 2011). 


\section{tempordilis}

Assim, compreendemos, que o capital tem gerenciado os investimentos na área educacional e as grandes mudanças no interior da mesma, não são de ordens pedagógicas, produção de novos conhecimentos, investimentos em formação docente, pesquisa e extensão; mas, contrariando os princípios que norteiam a concepção de educação emancipatória, crítica e reflexiva, tais instituições empreendem uma verdadeira luta na "captação" de novos alunos, considerando-os meras mercadorias e passíveis de exploração e subordinação. Além disso, a redução de custos estrangula a classe trabalhadora docente, seus técnicos administrativos entre outros e, lamentavelmente, desqualifica cada vez mais a educação e a formação profissional. Temos aqui, cabalmente, a barbárie da educação superior no Brasil e o recrudescimento do capital financeiro - contudo está dado um mercado para os empresários da educação, aquilo que concordamos ser o empresariamento educacional - deixando a educação para a formação profissional (FP) qualificada, apenas para a luta dos movimentos sociais, dos docentes comprometidos e os dos próprios estudantes com um pouco mais de discernimento da conjuntura atual, sem considerar que o próprio Estado tem desqualificado este movimento.

\section{Formação profissional em serviço social no brasil em tempos de privatização e sucateamento da política educacional}

O Serviço Social se institucionaliza como profissão a partir da década de 1930 sob a égide do Estado, do empresariado e da doutrina da Igreja Católica, no intuito de enfrentar as manifestações da questão social, sobretudo, no contexto de pauperização da classe trabaIhadora no acirramento da industrialização brasileira. O conservadorismo, portanto, é uma marca presente na emergência da profissão, atualizando e reforçando as bases de manutenção da ordem capitalista.

O Estado, pressionado a regular as relações sociais, tanto no sentido de viabilizar o processo de acumulação capitalista como no atendimento das demandas da classe trabalhadora elabora políticas sociais que abrem um espaço de trabalho para os Assistentes Sociais brasileiros. Estas políticas sociais, através da intervenção destes profissionais se traduzem em espaços de produção e reprodução social das relações sociais capitalistas, legitimando assim o Serviço Social como uma profissão inscrita na divisão social e técnica do trabalho 


\section{temporalis}

que intervém nestas contradições da realidade social.

A partir dos anos 1960 a profissão inicia um processo de questionamento dos referenciais teóricos e políticos conservadores, sendo possível neste momento, analisar a conjuntura histórica e juntamente com toda a América Latina criar um movimento que se denotou de Movimento de Reconceituação do Serviço Social. Cabe destacar, que no bojo deste movimento e de seus desdobramentos históricos se definem uma aproximação e interlocução com os fundamentos da teoria social marxista. Interlocução esta que possibilitou a construção de um novo projeto ético-político da profissão (PEP), culminando com a revisão profícua dos códigos de ética precedentes ao de 1993, o qual está em vigência atualmente, bem como, reatualizar a lei de regulamentação da profissão neste mesmo ano. Estes novos princípios ético-políticos se expressam, todavia, nas diretrizes curriculares da ABEPSS (1996) para a formação profissional em Serviço Social, haja vista, o amplo debate que esta entidade deflagrou em meados dos anos 1990 com toda a categoria profissional, sendo estudantes, docentes, profissionais e as Unidades de Formação Acadêmica.

Sendo assim, o novo projeto ético-político profissional traz em seu arcabouço, entre outros princípios, uma intransigente defesa dos direitos sociais construídos historicamente, a luta e resistência contra toda forma de opressão e preconceito, bem como, um direcionamento rumo à construção de uma nova ordem societária, livre da propriedade privada e da divisão de classes sociais.

É notório frisar que diante de tudo que vimos conceituando, implica dizer que a FP em Serviço Social "[...] está profundamente ameaçada na atualidade!" (BRAZ; RODRIGUES, 2013, p. 256), assim, como o PEP, isto é, o direcionamento social, cultural, ético e político que dão concretude ao processo formativo dos assistentes sociais, estão sob o ataque do capital, do neoliberalismo de estado, das reformas educacionais e do empresariamento da educação - sendo estes os inúmeros desafios que se colocam para a FP e para a ABEPSS em tempos atuais.

Ainda, Braz e Rodrigues (2013, p. 256, grifos dos autores) nos apresentam uma relação existente entre as duas dimensões (FP e PEP), envolvendo dois importantes aspectos:

a) a produção de conhecimento em si que direciona $e$ conduz os rumos da FP e que, concomitantemente, for- 


\section{tempordils}

nece o contorno teórico ao PEP, configurando-se como a sua base teórica, presente em todo e qualquer projeto coletivo; b) a construção de determinado perfil profissional que se almeja. Tal perfil profissional é o elo fundamental que liga a FP ao PEP. A reprodução do PEP passa pela reprodução desse perfil profissional, o que, por sua vez, supõe uma determinada FP.

$E$, são exatamente ambas, dimensões e relações, que organicamente vinculadas estão ameaçadas diante da análise de conjuntura que já delineamos. Segundo os autores supracitados, a degradação da FP se mostra ainda mais avassaladora, se adicionarmos a essa análise o seguinte quadro: "[...] são 74.474 matrículas nos cursos EaD em Serviço Social, informada no Censo de Ensino Superior do MEC do ano de 2010" (BRAZ; RODRIGUES, 2013, p. 256) - modalidade de ensino mais deteriorada, dada a suscetível formação despolitizada, que privam o acesso do aluno não só à pesquisa e à extensão, como também, da vivência do debate acadêmico no âmbito universitário. $E$, acrescentam, mais um importante dado - dentre os cursos de Serviço Social presencial e a distância abrangeram, no ano de 2010, o total de 143.198 matriculados e desse universo uma parcela ínfima, cerca de 20\% (31.099 matrículas), estava alocada em cursos presenciais pertencentes a IES universitárias. Convém sublinhar que o curso de Serviço Social no Brasil, na modalidade a distância (EaD), ocupa o terceiro lugar no montante de alunos matriculados nesta modalidade, sendo antecedido apenas pelos cursos de Pedagogia e Administração (MEC-INEP, 2010 apud BRAZ; RODRIGUES, 2013, p. 272-273).

\section{Considerações Finais}

A partir das ideias discutidas neste artigo, pode-se concluir que com a entrada do ideário neoliberal, a privatização das políticas sociais, inclusive da política de educação superior, se consolida, o que ameaça veementemente a educação superior como direito social, e, fortalece seu empresariamento. Isso é demonstrado claramente neste artigo através dos dados apresentados e das legislações aprovadas pelos governos recentes, como o PNE - 2011/2020, aprovado em 2013 pelo Senado Federal.

A educação superior, desta forma, torna-se um nicho de exploração do capital, altamente rentável, possibilitando a formação de 


\section{temporollis}

grandes monopólios da educação superior. À medida que estes monopólios se solidificam a formação profissional oferecida pelos mesmos se deteriora, uma vez que torna-se mera mercadoria, despida dos elementos essenciais à uma formação profissional qualificada.

A formação profissional em Serviço Social embebedada por esta lógica - a da educação como mercadoria - e, ainda, pela lógica da educação a distância, sofre os reveses das mesmas, o que coloca em xeque as diretrizes curriculares de 1996 e o próprio projeto ético-político dos assistentes sociais, deflagrando uma situação de ameaça à qualidade da formação de novos e novas assistentes sociais.

Desta feita, esta realidade apresentada suscita vários desafios para a defesa de uma formação profissional qualificada ética, política, teórica e metodologicamente. A ABEPSS, gestão 2015-2016, preocupada com estas questões, coloca em seu planejamento para a gestão alguns desafios e ações fundamentais à resistência do sucateamento da formação profissional. Dentre as principais ações, pode-se citar:

- Realizar reuniões e gestões junto ao CNE/INEP/MEC ${ }^{10}$ para discutir a qualidade do ensino na graduação e os processos e formas de avaliação dos cursos;

- Promover a divulgação do mapeamento ${ }^{11}$ dos docentes e suas condições de trabalho;

- Promover ações junto às universidades públicas para abertura de novos cursos de Serviço Social de graduação e pós-graduação;

- Realizar um amplo debate nacional em comemoração aos 20 anos das Diretrizes Curriculares da ABEPSS de 1996; 80 anos de profissão e 70 anos da ABEPSS;

- Construir propostas de ações alternativas ao Sinaes ${ }^{12}$ com o ANDES - SN e outros sujeitos coletivos;

10 Órgãos fundamentais na gestão da política de educação superior no Brasil: Conselho Nacional de Educação (CNE), Instituto Nacional de Estudos e Pesquisas Educacionais Anísio Teixeira (INEP) e Ministério da Educação (MEC).

11 A gestão anterior da ABEPSS (2013-2014) realizou uma pesquisa acerca das condições de trabalho dos docentes envolvidos na formação profissional em Serviço Social. Cabe a gestão atual promover a divulgação e debate desta pesquisa.

12 Sistema Nacional de Avaliação da Educação Superior. 
- Solicitar a regulamentação da PNE/ABEPSS junto ao $\mathrm{MEC} / \mathrm{CNE}$

- Dar continuidade ao Projeto “ABEPSS Itinerante”"14;

- Propor ações que qualifiquem a formação presencial dos cursos de graduação em Serviço Social. (ABEPSS, 2015).

Por meio dessas estratégias/ações almeja-se resistir à precarização da formação superior em Serviço Social e elevar os pressupostos defendidos pelas diretrizes curriculares de 1996 e pelo próprio projeto ético-político dos assistentes sociais brasileiros. Assim, a atual gestão da ABEPSS tem agido de acordo com o lema de sua gestão, mantendo concomitantemente: "Ousadia e sonhos em tempos de resistência".

\section{REFERÊNCIAS}

ABEPSS. Associação Brasileira de Ensino e Pesquisa em Serviço Social. Diretrizes Gerais para o Curso de Serviço Social. (Com base no Currículo Mínimo aprovado em Assembleia Geral Extraordinária de 8 de novembro de 1996). Cadernos ABESS, São Paulo, n. 7, ed. esp., p. 58$76,1997$.

. Projeto “ABEPSS Itinerante": as diretrizes curriculares e o projeto de formação profissional do Serviço Social. Juiz de Fora/MG, 2011. Disponível em: <http://pt.scribd.com/doc/106292141/Projeto-ABEPSS-Itinerante-para-divulgacao-25-03-12>. Acesso em: 10 jan. 2014.

. Planejamento de Ações: biênio (2015-2016). São Paulo, 2015.

13 Política Nacional de Estágio em Serviço Social elaborada de maneira participativa pela ABEPSS.

14 O Projeto "ABEPSS Itinerante" formulado na gestão da ABEPSS (2011-2012) tem como principal objetivo: "Fortalecer as estratégias político-pedagógicas de enfrentamento à precarização do ensino superior, por meio da difusão ampla dos princípios, conteúdos e desafios colocados para a consolidação das DCs como instrumento fundamental na formação de novos profissionais (reforço dos eixos: Fundamentos, Trabalho, Questão Social, Ética, Pesquisa e Ensino da prática)". (ABEPSS, 2011, p. 13). 


\section{temporolis}

ANDES-SN. Sindicato Nacional dos Docentes das Instituições de Ensino Superior. Análise do Projeto de Lei $n^{\circ} 7200 / 2006$ : a educação superior em perigo! Circular n. 299/06. Brasília-DF, 22 set. 2006. Disponível em: <http://www.sintunesp.org.br/refuniv/Andes-SN-An\%C3\%A1lise_ PL7200-06.pdf>. Acesso em: 8 jan. 2014.

BEHRING, Elaine Rossetti. Brasil em contra-reforma: desestruturação do Estado e perda de direitos. 2. ed. São Paulo: Cortez, 2008.

BRASIL. Decreto n. 5.622, de 19 de dezembro de 2005. Regulamenta o art. 80 da Lei $n^{\circ}$ 9.394, de 20 de dezembro de 1996, que estabelece as diretrizes e bases da educação nacional. Diário Oficial da União, Poder Executivo, Brasília, DF, 20 dez. 2005. p. 1. Disponível em: <http:// www.planalto.gov.br/ccivil_03/_ato2004-2006/2005/Decreto/D5622. htm>. Acesso em: 22 mar. 2013.

. Lei n. 10.861, de 14 de abril de 2004. Institui o Sistema Nacional de Avaliação da Educação Superior - SINAES e dá outras providências. Diário Oficial da União, Poder Executivo, Brasília, DF, 15 abr. 2004. p. 4. Disponível em: <http://www.planalto.gov.br/ccivil_03/_ato20042006/2004/lei/l10.861.htm >. Acesso em: 22 mar. 2014.

. Lei n. 11.096, de 13 de janeiro de 2005. Institui o Programa Universidade para Todos - PROUNI, regula a atuação de entidades beneficentes de assistência social no ensino superior; altera a Lei $n^{\circ} 10.891$, de 9 de julho de 2004, e dá outras providências. Diário Oficial da União, Poder Executivo, Brasília, DF, 14 jun. 2005. p. 7. Disponível em: <http:// www.planalto.gov.br/ccivil_03/_ato2004-2006/2005/lei/L11096.htm>. Acesso em: 6 jan. 2013.

. Lei n.9.394, de 20 de dezembro de 1996. Estabelece as diretrizes e bases da educação nacional. Diário Oficial da União, Poder Legislativo, Brasília, DF, 23 dez. 1996. p. 27.833. Disponível em: <http:// www.planalto.gov.br/ccivil_03/leis/l9394.htm>. Acesso em: 16 mar. 2013.

BRAZ, Marcelo, RODRIGUES, Mavi. O ensino em Serviço Social da era 


\section{temporolis}

neoliberal (1990-2010): avanços, retrocessos e enormes desafios. In: SILVA, José Fernando Siqueira. SANT'ANA, Raquel Santos. LOURENÇO, Edvânia. Ângela de Souza. (Org.). Sociabilidade burguesa e Serviço Social. Rio de Janeiro: Lumen Juris, 2013.

CÂMARA DOS DEPUTADOS. Projeto de Lei 7.200, de 12 de junho de 2006. Estabelece normas gerais da educação superior, regula a educação superior no sistema federal de ensino, altera as Leis n's 9.394, de 20 de dezembro de 1996; 8.958, de 20 de dezembro de 1994; 9.504, de 30 de setembro de 1997; 9.532, de 10 de dezembro de 1997; 9.870, de 23 de novembro de 1999; e dá outras providências. Diário da Câmara dos Deputados, Brasília, DF, 15 jun. 2006. p. 30223-30236. Disponível em: http://www.camara.gov.br/proposicoesWeb/fichadetramitacao?idProposicao=327390 Acesso em: 10 jan. 2014.

CASTELO, Rodrigo. O social-liberalismo: auge e crise da supremacia burguesa na era neoliberal. São Paulo: Expressão Popular, 2013.

CEOLIN, George Francisco; SILVA, Neimy Batista. Desafio da ABEPSS Itinerante na defesa da qualidade na formação em Serviço Social. Temporalis, Brasília, DF, ano 13, n. 25, p. 155-179, jan./jun. 2013.

IAMAMOTO, Marilda Vilela. O Serviço Social na contemporaneidade: trabalho e formação profissional. 3. ed. São Paulo: Cortez, 2000.

LEHER, Roberto. Universidade, socialismo e consciência social: Florestan Fernandes na revista Universidade e Sociedade. Universidade e Sociedade, Brasília, DF, ano 20, n.47, p. 17-29, fev. 2011.

- Novo plano de governo visa consagrar prevalência do setor privado no financiamento da educação. Correio da Cidadania, São Paulo, 22 jan. 2014. Disponível em: <http://www.correiocidadania. com.br/index.php?option=com_content\&view=article\&id=9254:manchete220114\&catid=34:manchete $>$. Acesso em: 21 jan. 2014. 


\section{temporalis}

MATTOSO, Jorge. A desordem do trabalho. São Paulo: Scritta, 1995.

MINTO, Lalo Watanabe.; MINTO, Cesar Augusto. Incríveis legados da "reforma universitária" de 1968. Revista Pensata, Guarulhos, v. 1, n. 3, p. 72-89, dez. 2012. Disponível em: <http://www.unifesp.br/revistas/ pensata/wp-content/uploads/2013/01/Pensata-final.pdf >. Acesso em: 12 jan. 2014.

NEVES, Lúcia Maria Wanderley; PRONKO, Marcela Alejandra O mercado do conhecimento e o conhecimento para o mercado: da formação para o trabalho complexo no Brasil contemporâneo. Rio de Janeiro: EPSJV, 2008.

SADER, E.; GENTILI, P. BORÓN, A. (orgs.). Pós-neoliberalismo: as políticas sociais e o Estado democrático. São Paulo: Paz e Terra, 1995. 